\title{
Integrated measurements of acoustical and optical thin layers II: Horizontal length scales
}

\author{
Mark A. Moline ${ }^{\mathrm{a}}$, Kelly J. Benoit-Bird ${ }^{\mathrm{b}}$, Ian C. Robbins ${ }^{\mathrm{a}}$, Maddie Schroth-Miller ${ }^{\mathrm{c}}$, Chad M. Waluk ${ }^{\mathrm{b}}$, \\ Brian Zelenke ${ }^{a}$ \\ a Biological Sciences Department, Center for Marine and Coastal Sciences, California Polytechnic State University, San Luis Obispo, CA 93407, USA \\ ${ }^{\mathrm{b}}$ College of Oceanic and Atmospheric Sciences, Oregon State University, 104 COAS Administration Building, Corvallis, OR 97331, USA \\ c Mathematics Department, Center for Marine and Coastal Sciences, California Polytechnic State University, San Luis Obispo, CA 93407, USA
}

\begin{abstract}
A B S T R A C T
The degree of layered organization of planktonic organisms in coastal systems impacts trophic interactions, the vertical availability of nutrients, and many biological rate processes. While there is reasonable characterization of the vertical structure of these phenomena, the extent and horizontal length scale of variation has rarely been addressed. Here we extend the examination of the vertical scale in the first paper of the series to the horizontal scale with combined shipboard acoustic measurements and bio-optic measurements taken on an autonomous underwater vehicle. Measurements were made in Monterey Bay, CA from 2002 to 2008 for the bio-optical parameters and during 2006 for acoustic scattering measurements. The combined data set was used to evaluate the horizontal decorrelation length scales of the bio-optical and acoustic scattering layers themselves. Because biological layers are often decoupled from the physical structure of the water column, assessment of the variance within identified layers was appropriate. This differs from other studies in that physical parameters were not used as a basis for the layer definition. There was a significant diel pattern to the decorrelation length scale for acoustic layers with the more abundant nighttime layers showing less horizontal variability despite their smaller horizontal extent. A significant decrease in the decorrelation length scale was found in bio-optical parameters over six years of study, coinciding with a documented shift in the plankton community. Results highlight the importance of considering plankton behavior and time of day with respect to scale when studying layers, and the challenges of sampling these phenomena.
\end{abstract}

\section{Introduction}

Mediation, persistence, and variability in rates of biogeochemical cycling are primarily defined by the structure and activity of biological communities. Communities are organized non-randomly, and can be layered due to the physical structure of water, distribution of nutrients, advective processes, and behavioral differences within and between organisms (Deutschman et al., 1993). Because of these varied mechanisms for accumulation of different planktonic organisms, their horizontal and vertical distributions are often heterogeneous, vary between taxonomic groups, and are scaled to the physical, chemical, and biological forcing. One extreme example of this heterogeneous organization, which has received considerable attention in recent decades, is the common occurrence of thin layers in coastal regions (Cheriton et al., 2007). These dense accumulations of plankton are defined by their small vertical scales of tens of centimeters to a few meters, yet can be continuous over many kilometers (Donaghay et al., 1992; Dekshenieks et al., 2001; Holliday et al., 2003;
McManus et al., 2003). Through these recent studies, much has been learned about the formation of these layers (Osborn 1998; McManus et al., 2003; Birch et al., 2008; Ryan et al., 2008b), biological communities that make up layers (Donaghay et al., 1992; Rines et al., 2002; Menden-Deuer, 2008; Rines et al., this issue), and the time dependent changes of layers (McManus et al., 2003; Cheriton et al., 2007).

Although the horizontal extent of thin layers has been documented (Dekshenieks et al., 2001), what is not known well is horizontal continuity of layers and specifically what the horizontal length scales of variability are for these phenomena. While a number of studies have quantified the scales of chlorophyll fluorescence as it relates to variance of temperature and salinity over larger domains (Lee et al., 2000; Rudnick et al., 2004; Hodges and Rudnick, 2006; Cheriton et al., this issue), significantly less has been done on small scales and, in particular, layers (Blackwell et al., 2008). This is despite evidence showing decreasing length scales and their importance in modulating distributions of biological communities and optical variability 
when approaching coastlines (Yoder and McClain, 1987; Lovejoy et al., 2001; Chang et al., 2002; Bissett et al., 2004). As biological interactions, biogeochemical cycling, and the optical properties of the water column are influenced by these layers (Sullivan et al., 2009), and likely dependent on the distribution and scales of layers in coastal systems.

One of the initial challenges in studying thin layers was that traditional approaches were not adequate in resolving small scale structure (Cowles et al., 1998). Developments in profilers and slow-drop packages have significantly improved resolution within layers for a number of parameters, in particular the small scale physical dynamics in and around layers (Wang and Goodman, this issue). Evaluation of thin layers in three dimensions, addressing their horizontal extent, is even more challenging. Although we are not able to synoptically assess vertical and horizontal extent of layers, there are a number of technologies and platforms that can make these measurements over varying periods of time, including tow packages (Dale et al., 2006), autonomous underwater platforms (Yu et al., 2002; Dickey et al., 2008; Ryan et al., this issue), and recently airborne LIDAR (Churnside et al., 2006).

Another challenging aspect of the studying thin layers is making concurrent measurement of multiple trophic levels. Measurements have traditionally focused on either phytoplankton layers (Cowles et al., 1998; Dekshenieks et al., 2001; McManus et al., 2008; Osborn, 1998; Rines et al., 2002a; Sullivan et al., 2005) or zooplankton layers (Cheriton et al., 2007; Holliday et al., 2003, 1998; McManus et al., 2005; Widder et al., 1999), but they have rarely been studied together (Benoit-Bird et al., 2009; Donaghay et al., 1992; Gallager et al., 2004; McManus et al., 2003). Assessing layers by focused attention on one component of the planktonic community necessarily excludes evaluation of the influence of other organisms. An example showing the advantages of simultaneous measurements in evaluating layer interactions is presented in the first of these companion papers (Benoit-Bird et al., 2009).

In this second paper, we attempt to quantify and evaluate the horizontal scales of both bio-optical and acoustical thin layers in the northeast section of Monterey Bay with data from 2002 through 2008, with a focus on field data from the interdisciplinary research initiative termed Layered Organization in the Coastal Ocean (LOCO) in 2006. Utilizing both autonomous underwater vehicles (AUVs) and ship-based sampling of fluorescent, bioluminescent, and acoustically scattering layers, we identify the decorrelation length scales for these parameters. These descriptions of the spatial distance over which neighboring data points are correlated provide the threshold point above which the variance in plankton abundance no longer changes, defining a statistical distance which layers are coherent. These scales elucidate the resolution and extent necessary for the future sampling of horizontal distributions of thin layers, and are relevant for evaluating biogeochemical processes, which are significantly and disproportionately mediated by layered structure in the coastal ocean.

\section{Methods}

Sampling was conducted in the northeast portion of Monterey Bay, California, USA bounded to the West by $122.071^{\circ} \mathrm{W}$ and to the South by $36.744^{\circ} \mathrm{N}$ (Fig. 1). Data from two AUV platforms sampling between August, 2002 and October, 2008, and one shipboard platform in August, 2006 are used for this study, which includes the period of intensive investigation of layers during the 2006 LOCO field experiment. These platforms collected continuous horizontal measurements of physical, bio-optical, and acoustical properties of the water column that are used here to assess the critical horizontal length scales of variability within layers.

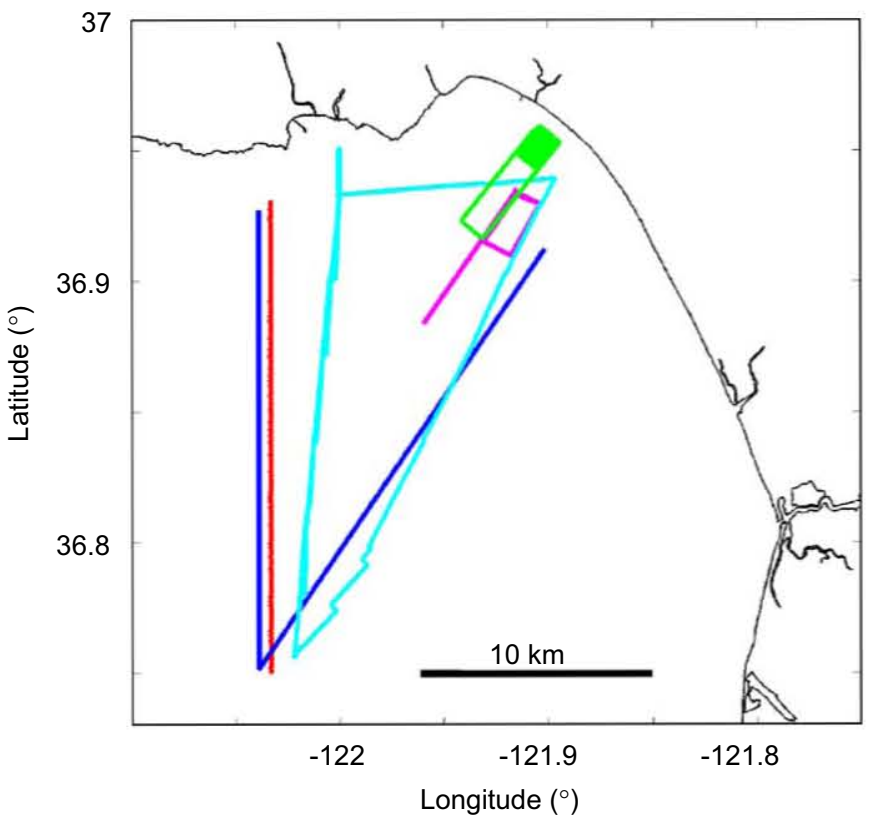

Fig. 1. A map of the northeast region of Monterey Bay, California, USA and sampling tracks of the REMUS AUVs for physical and bio-optical properties. Tracks are color coded based on field experiment in MUSE project in 2002 (red), Autonomous Ocean Sampling Network II (AOSN) project in 2003 (blue), the Layered Organization in Coastal Ocean (LOCO) field effort in 2006 (green), the independent follow on to LOCO (magenta; see Benoit-Bird et al., this issue), the ESPreSSO/BioSPACE/MB08 combined experiment in 2008 (light blue). Acoustic data were collected from the R/V Shana Rae within the areas colored magenta and green. (For interpretation of the references to colour in this figure legend, the reader is referred to the web version of this article.)

\subsection{Bio-optical sampling}

The bio-optical data, including chlorophyll fluorescence, optical backscatter, fluorescence, and bioluminescence, were obtained by sensor suites integrated into two REMUS AUV systems (Moline et al., 2005). The vehicles were generally programmed to undulate between $2 \mathrm{~m}$ depth and $3 \mathrm{~m}$ altitude above a variable bottom depth at a speed of approximately $2 \mathrm{~m} / \mathrm{s}$. Navigation of the AUV was conducted by acoustical navigation, by repeated surface GPS fixes, or occasionally by a combination of the two methods. Acoustical navigation continuously triangulated the position of the vehicle using an array of digital acoustic transponders deployed in the area of study for the mission duration. This approach was used when the vehicle was operating in a relatively restricted area, as during the LOCO experiment in 2006 (Fig. 1; Benoit-Bird et al., this issue). When the vehicles were transecting a larger portion of the bay, they would surface every $3-5 \mathrm{~km}$ for a GPS position and would reacquire the programmed track-line and attempt to maintain it using an internal compass. Error in horizontal position from the acoustical navigation approach is largely based on GPS errors for the transponders. Here, the horizontal position uncertainty for the vehicles is estimated at $<5 \mathrm{~m}$ (Hibler et al., 2008). For navigation using the repeated surfacing, the horizontal position error is based on both compass error $\left(\sim 2.3^{\circ}\right.$; Moline et al., 2005$)$ and any drift due to currents when the vehicle is not within $20 \mathrm{~m}$ of the bottom for bottom-lock Doppler Velocity Log (DVL). Given the mean distance between surface fixes, the mean error was $\sim 50 \mathrm{~m}$. With the sampling frequency of the sensors and the speed of the vehicle nominally $2 \mathrm{~ms}^{-1}$, the vertical resolution of the measurements was $0.15 \pm 0.10 \mathrm{~m}$. 
Table 1a

Summary statistics for chlorophyll a and bioluminescent layers.

\begin{tabular}{|c|c|c|c|c|c|c|c|c|c|c|c|}
\hline Date & $\begin{array}{l}\text { \# } \\
\text { Profiles }\end{array}$ & $\begin{array}{l}\text { Chlorophyll a } \\
\rightarrow \\
\% \text { layers }\end{array}$ & $\begin{array}{l}\text { De-correlation } \\
\text { Length scale } \\
(\mathrm{km})\end{array}$ & $\begin{array}{l}\text { FWHM } \\
\text { (m) (std.) }\end{array}$ & $\begin{array}{l}\text { Layer Z } \\
\text { (m) (std.) }\end{array}$ & $\begin{array}{l}\text { Ratio } \\
\text { L/WC }\end{array}$ & $\begin{array}{l}\text { Biolumines- } \\
\text { cence } \rightarrow \\
\% \text { layers }\end{array}$ & $\begin{array}{l}\text { De-correlation } \\
\text { Length scale } \\
(\mathrm{km})\end{array}$ & $\begin{array}{l}\text { FWHM } \\
\text { (m) (std.) }\end{array}$ & $\begin{array}{l}\text { Layer Z } \\
\text { (m) (std.) }\end{array}$ & $\begin{array}{l}\text { Ratio } \\
\text { L/WC }\end{array}$ \\
\hline 082002 & 56 & 48 & 7.04 & $0.91(0.51)$ & $10.02(5.60)$ & 2.97 & 3 & 3.08 & $\mathbf{0 . 0 8}(0.08)$ & $21.14(16.77)$ & 1.01 \\
\hline 082202 & 44 & 29 & 3.70 & $\mathbf{0 . 6 3}(0.42)$ & $12.42(7.74)$ & 2.11 & 11 & 2.61 & $\mathbf{0 . 1 5}(0.13)$ & $22.21(11.94)$ & 0.97 \\
\hline 082402 & 61 & 24 & 7.58 & $\mathbf{0 . 6 5}(0.42)$ & 11.09 & 2.00 & 34 & 3.87 & $\mathbf{0 . 2 6}(0.23)$ & $\mathbf{3 7 . 0 0}(2.34)$ & 0.98 \\
\hline 082502 & 60 & 35 & 3.58 & $0.72(0.46)$ & $10.46(4.30)$ & 2.32 & 48 & 0.82 & $0.40(0.25)$ & $32.27(4.66)$ & 1.00 \\
\hline 081003 & 186 & 63 & 9.83 & $\mathbf{0 . 8 4}(0.60)$ & $10.69(6.71)$ & 2.29 & 4 & 2.65 & $\mathbf{0 . 4 1}(0.31)$ & $28.01(8.02)$ & 1.00 \\
\hline 081103 & 192 & 60 & 7.26 & $\mathbf{0 . 8 7}(0.49)$ & $10.11(4.81)$ & 2.50 & 19 & 3.87 & $\mathbf{0 . 3 2}(0.23)$ & $14.53(11.32)$ & 0.99 \\
\hline 081203 & 195 & 42 & 7.39 & $\mathbf{0 . 8 3}(0.52)$ & $8.69(4.62)$ & 2.14 & 37 & 4.74 & $\mathbf{0 . 2 6}(0.19)$ & $14.58(9.80)$ & 0.98 \\
\hline 081303 & 202 & 44 & 5.91 & $\mathbf{0 . 8 6}(0.48)$ & $10.70(5.66)$ & 2.09 & 57 & 2.22 & $\mathbf{0 . 3 5}(0.32)$ & $16.47(10.30)$ & 1.00 \\
\hline 081403 & 183 & 39 & 9.50 & $\mathbf{0 . 6 0}(0.47)$ & $18.63(10.78)$ & 1.27 & 54 & 0.13 & $\mathbf{0 . 3 3}(0.30)$ & 19.75 (11.29) & 0.99 \\
\hline 081503 & 182 & 48 & 4.20 & $\mathbf{0 . 9 4}(0.62)$ & $12.44(7.19)$ & 2.05 & 48 & 3.54 & $\mathbf{0 . 3 4}(0.28)$ & $18.67(12.06)$ & 0.98 \\
\hline 081603 & 179 & 41 & 5.06 & $0.96(0.47)$ & $8.19(6.04)$ & 2.23 & 30 & 2.16 & $\mathbf{0 . 3 8}(0.37)$ & $27.00(9.89)$ & 1.00 \\
\hline 081703 & 183 & 55 & 5.61 & $1.03(0.60)$ & $13.01(9.48)$ & 2.11 & 44 & 6.65 & $\mathbf{0 . 3 1}(0.24)$ & $20.76(10.23)$ & 1.01 \\
\hline 081803 & 188 & 59 & 11.22 & $1.09(0.49)$ & $10.83(7.00)$ & 2.01 & 23 & 5.00 & $0.33(0.30)$ & $24.74(10.93)$ & 0.97 \\
\hline 071206 & 111 & 89 & 0.24 & $1.14(0.57)$ & $6.00(2.76)$ & 1.22 & - & - & - & - & - \\
\hline 071306 & 253 & 80 & 0.21 & $1.25(0.51)$ & $6.05(2.42)$ & 1.29 & - & - & - & - & - \\
\hline 071406 & 435 & 88 & 0.08 & $1.09(0.49)$ & $3.98(1.85)$ & 1.30 & - & - & - & - & - \\
\hline 071506a & 140 & 53 & 0.11 & $1.10(0.37)$ & $4.16(1.64)$ & 1.31 & - & - & - & - & - \\
\hline 071506b & 300 & 24 & 0.21 & $\mathbf{0 . 6 2}(0.47)$ & $12.41(2.82)$ & 1.09 & No layer & 0.40 & - & - & - \\
\hline 071606 & 125 & 67 & 0.52 & $1.06(0.42)$ & $5.07(2.11)$ & 1.53 & - & - & - & - & - \\
\hline 071706 & 113 & 92 & 1.20 & $1.00(0.42)$ & $4.21(1.62)$ & 1.79 & - & - & - & - & - \\
\hline 080406 & 164 & 75 & 0.42 & $1.22(0.49)$ & $6.77(2.26)$ & 2.00 & No layer & 0.57 & - & - & - \\
\hline 080606 & 338 & 92 & 0.09 & $1.25(0.50)$ & $10.65(2.40)$ & 1.83 & No layer & 0.03 & - & - & - \\
\hline 080706 & 329 & 90 & 0.75 & $1.22(0.49)$ & $9.85(2.12)$ & 2.20 & No layer & 0.02 & - & - & - \\
\hline 060408 & 128 & 80 & 3.21 & $\mathbf{0 . 3 6}(0.36)$ & $13.29(10.17)$ & 1.49 & - & - & - & - & - \\
\hline 061008 & 146 & 84 & 0.52 & $\mathbf{0 . 5 5}(0.49)$ & $7.82(4.37)$ & 1.87 & - & - & - & - & - \\
\hline 061108 & 144 & 92 & 0.88 & $\mathbf{0 . 6 2}(0.50)$ & $7.77(4.52)$ & 2.00 & - & - & - & - & - \\
\hline 061208 & 121 & 90 & 1.47 & $\mathbf{0 . 6 3}(0.51)$ & $6.59(4.16)$ & 2.43 & - & - & - & - & - \\
\hline 061308 & 142 & 75 & 0.21 & $\mathbf{0 . 5 7}(0.46)$ & $8.97(9.54)$ & 2.06 & - & - & - & - & - \\
\hline 061408 & 116 & 83 & 2.08 & $\mathbf{0 . 7 1}(0.62)$ & $9.61(9.21)$ & 2.37 & - & - & - & - & - \\
\hline 101408 & 146 & 92 & 2.01 & $\mathbf{0 . 3 8}(0.37)$ & 9.51 (5.69) & 1.97 & - & - & - & - & - \\
\hline 101508 & 248 & 82 & 4.01 & $\mathbf{0 . 3 2}(0.32)$ & $6.75(3.44)$ & 1.90 & - & - & - & - & - \\
\hline 101608 & 250 & 79 & 1.49 & $0.39(0.41)$ & 7.22 (3.78) & 1.86 & - & - & - & - & - \\
\hline 101808 & 258 & 69 & 3.52 & $0.42(0.41)$ & 8.49 (5.69) & 1.47 & - & - & - & - & - \\
\hline $101908 a$ & 240 & 77 & 0.74 & $\mathbf{0 . 3 2}(0.36)$ & $8.04(5.40)$ & 1.41 & - & - & - & - & - \\
\hline $101908 b$ & 90 & 83 & 0.16 & $\mathbf{1 . 0 8}(0.62)$ & $7.67(5.85)$ & 1.44 & 50 & 0.18 & $0.49(0.33)$ & $20.56(11.83)$ & 1.02 \\
\hline 102108 & 236 & 77 & 0.68 & $\mathbf{0 . 5 1}(0.49)$ & 7.48 (6.47) & 1.65 & - & - & - & - & - \\
\hline 102208 & 219 & 52 & 0.29 & $\mathbf{0 . 3 4}(0.35)$ & 9.68 (7.53) & 1.67 & - & - & - & - & - \\
\hline
\end{tabular}

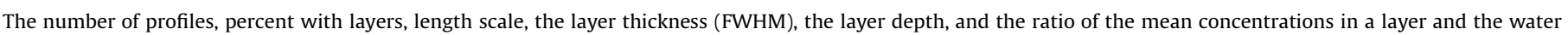
column is shown.

The two vehicles provided measures of chlorophyll fluorescence (Wetlabs Inc. ECO-triplet, Philomath, OR and Seapoint Sensors, Inc., Exeter NH), optical backscatter (Wetlabs Inc. ECOtriplet, Philomath, OR and Seapoint Sensors, Inc., Exeter NH), and, on one vehicle, a bioluminescence bathyphotometer. The fluorometers were factory calibrated to provide values of chlorophyll a using cultures of $T$. weissflogii and adjusted in the field using natural phytoplankton communities. As the vehicles were operating at depth in waters with relatively high attenuation and/or at night, fluorescence quenching was found not to influence the chlorophyll a values reported here. The bathyphotometer is described in Herren et al., (2005) but briefly, a centrifugal-type impeller pump drives water into an enclosed $500 \mathrm{ml}$ chamber and creates turbulent flow, which mechanically stimulates bioluminescence. The measure of $\mathrm{BP}$ is therefore an index of the total luminescent capacity of organisms in a set water volume. A flow meter monitors pumping rates using a magnet and a Hall-effect sensor to generate a period signal, which is converted to an analog signal of flow rate. The flow rates are measured as the water passes from the detection chamber to exhaust outlets. In order to prevent premature stimulation of bioluminescence by the moving vehicle, water is taken directly through the front nose section of the vehicle. Two light baffling turns in the nose serve to eliminate ambient light contamination. No significant ram-effect on light production or flow rate from the vehicle itself has been found with this integrated system (Blackwell et al., 2002). Sampling with the REMUS outfitted with the bathyphotometer was conducted between 22:00 and 04:00 local time as bioluminescence is a diurnally dependant measure, but it has been shown to be generally stable during this $6 \mathrm{~h}$ period (Moline et al., 2001). Salinity and temperature measurements were made on both vehicles by OS200 CT sensors (Ocean Sensors, Inc., San Diego, CA) or by new Neil Brown CT sensors designed for use on AUV systems. Note that the sensor suites of the vehicles changed over the 6 years of measurements used in this study. As the analysis of length scale is based on relative horizontal change for each parameter for each mission, inter-calibration of sensors and comparison in absolute units between sensors is not required. The combined bio-optical data set used in this study represents 37 individual missions, producing a total of 6699 individual casts (Tables $1 \mathrm{a}$ and $1 \mathrm{~b}$ ).

\subsection{Acoustical measurements}

From 15 July to 8 August 2006, the area surrounding the LOCO mooring array was sampled using multi-frequency acoustics from the $16 \mathrm{~m} \mathrm{R/V}$ Shana Rae (Fig. 1, green and magenta areas). Sampling covered 8 days and 3 nights during this period (Table 2). Underway surveying from the R/V Shana Rae was 
Table 1b

Summary statistics for optical backscatter layers.

\begin{tabular}{|c|c|c|c|c|c|c|}
\hline Date & $\begin{array}{l}\# \\
\text { Profiles }\end{array}$ & $\begin{array}{l}\text { Optical } \\
\text { backscatter } \rightarrow \\
\text { \% Layers }\end{array}$ & $\begin{array}{l}\text { De- } \\
\text { correlation } \\
\text { Length scale } \\
(\mathrm{km})\end{array}$ & $\begin{array}{l}\text { FWHM } \\
\text { (m) (std.) }\end{array}$ & $\begin{array}{l}\text { Layer Z } \\
\text { (m) (std.) }\end{array}$ & $\begin{array}{l}\text { Ratio } \\
\text { L/WC }\end{array}$ \\
\hline 082002 & 56 & 0.73 & 6.49 & $0.27(0.30)$ & $20.42(9.52)$ & 1.33 \\
\hline 082202 & 44 & 0.61 & 3.80 & $0.48(0.51)$ & $23.91(9.63)$ & 1.51 \\
\hline 082402 & 61 & 0.75 & 0.78 & $0.45(0.41)$ & $22.66(10.70)$ & 1.74 \\
\hline 082502 & 60 & 0.70 & 0.55 & $0.30(0.35)$ & $21.55(11.26)$ & 1.10 \\
\hline 081003 & 186 & 0.86 & 8.07 & $0.63(0.52)$ & $15.76(10.38)$ & 1.46 \\
\hline 081103 & 192 & 0.89 & 6.85 & $0.44(0.40)$ & $15.57(9.87)$ & 1.34 \\
\hline 081203 & 195 & 0.90 & 4.72 & $0.49(0.49)$ & 17.17 (10.29) & 1.37 \\
\hline 081303 & 202 & 0.79 & 4.28 & $0.39(0.34)$ & $18.22(10.18)$ & 1.43 \\
\hline 081403 & 183 & 0.84 & 5.67 & $0.40(0.40)$ & $18.42(9.75)$ & 1.37 \\
\hline 081503 & 182 & 0.79 & 4.33 & $0.37(0.34)$ & $19.49(9.86)$ & 1.36 \\
\hline 081603 & 179 & 0.78 & 4.99 & $0.46(0.43)$ & $18.39(10.78)$ & 1.33 \\
\hline 081703 & 183 & 0.75 & 6.55 & $0.38(0.37)$ & $20.04(10.79)$ & 1.18 \\
\hline 081803 & 188 & 0.75 & 9.17 & $0.40(0.39)$ & $20.45(8.95)$ & 1.12 \\
\hline 071206 & 111 & 0.37 & 1.26 & $0.77(0.41)$ & $6.78(5.24)$ & 1.17 \\
\hline 071306 & 253 & 0.50 & 1.02 & $0.93(0.41)$ & $6.31(5.46)$ & 1.29 \\
\hline 071406 & 435 & 0.60 & 0.32 & $0.97(0.42)$ & $4.13(3.07)$ & 1.30 \\
\hline $071506 a$ & 140 & 0.19 & 0.65 & $0.98(0.43)$ & $4.49(2.84)$ & 1.31 \\
\hline $071506 b$ & 300 & 0.54 & 0.37 & $0.69(0.41)$ & $13.47(2.65)$ & 1.20 \\
\hline 071606 & 125 & 0.58 & 0.58 & $1.02(0.37)$ & $4.94(2.26)$ & 1.47 \\
\hline 071706 & 113 & 0.77 & 1.08 & $0.96(0.33)$ & $4.02(2.11)$ & 1.58 \\
\hline 080406 & 164 & 0.57 & 1.18 & $0.99(0.53)$ & $9.25(4.86)$ & 1.44 \\
\hline 080606 & 338 & 0.89 & 0.81 & $0.96(0.50)$ & $10.74(2.49)$ & 1.33 \\
\hline 080706 & 329 & 0.81 & 1.00 & $1.03(0.54)$ & $9.93(2.32)$ & 1.47 \\
\hline 060408 & 128 & 0.79 & 4.19 & $0.16(0.12)$ & $22.20(19.23)$ & 1.23 \\
\hline 061008 & 146 & 0.71 & 2.02 & $0.22(0.26)$ & 16.88 & 1.35 \\
\hline 061108 & 144 & 0.75 & 1.91 & $0.26(0.25)$ & $17.46(14.70)$ & 1.43 \\
\hline 061208 & 121 & 0.73 & 2.39 & $0.20(0.21)$ & $16.84(14.70)$ & 1.37 \\
\hline 061308 & 142 & 0.80 & 2.22 & $0.25(0.28)$ & $24.03(21.49)$ & 1.25 \\
\hline 061408 & 116 & 0.81 & 2.81 & $0.19(0.19)$ & 24.10 & 1.27 \\
\hline 101408 & 146 & 0.70 & 2.57 & $0.20(0.24)$ & 17.05 & 1.31 \\
\hline 101508 & 248 & 0.58 & 5.20 & $0.24(0.28)$ & 13.06 & 1.42 \\
\hline 101608 & 250 & 0.61 & 2.08 & $0.21(0.24)$ & 14.14 & 1.29 \\
\hline 101808 & 258 & 0.62 & 1.28 & $\mathbf{0 . 1 8}(0.23)$ & $15.28(15.45)$ & 1.26 \\
\hline $101908 a$ & 240 & 0.65 & 1.97 & $0.16(0.20)$ & $18.06(17.08)$ & 1.38 \\
\hline $101908 b$ & 90 & 0.21 & 0.41 & $1.01(0.62)$ & $13.57(9.58)$ & 1.33 \\
\hline 102108 & 236 & 0.48 & 1.93 & $0.24(0.33)$ & $20.31(16.27)$ & 1.37 \\
\hline 102208 & 219 & 0.43 & 1.30 & $0.28(0.34)$ & $20.30(17.83)$ & 1.63 \\
\hline
\end{tabular}

The number of profiles, percent with layers, length scale, the layer thickness (FWHM), the layer depth, and the ratio of the mean concentrations in a layer and the water column is shown.

conducted at a vessel speed of approximately $9 \mathrm{~km} \mathrm{~h}^{-1}$ with the transducers of a 38 and $120 \mathrm{kHz}$ split-beam echosounder (Simrad EK60 s) mounted $1 \mathrm{~m}$ beneath the surface on a rigid pole off the side of the vessel. The $120 \mathrm{kHz}$ echosounder, specifically used in this analysis to identify zooplankton scattering layers, had a $7^{\circ}$ beam and used a $64 \mu$ s pulse providing a vertical resolution of $2.5 \mathrm{~cm}$. The ping rate of the echosounder averaged $5-20 \mathrm{~Hz}$, providing an along track horizontal resolution of between 0.13 and $0.50 \mathrm{~m}$. Resolution was sometimes as small as $0.01 \mathrm{~m}$ along track because of increases in ping or a decrease in vessel speed for other operations. GPS location was recorded along with each echo so that the actual distance between subsequent data points was used for all analyses. The echosounder was calibrated in the field following the procedures of Foote et al. (1987) which is fully described in Benoit-Bird et al. (this issue). Echosounder data were analyzed in Myriax's Echoview software. A threshold of $-80 \mathrm{~dB}$ was applied to data from the $120 \mathrm{kHz}$ echosounder before analysis for thin layers.

To validate the assessment of zooplankton using acoustic methods, vertical net tows were periodically conducted with a 0.75 diameter, $333 \mu \mathrm{m}$ mesh net equipped with a General Oceanics flowmeter to allow calculation of volume sampled. The net was lowered until a weight $3 \mathrm{~m}$ from the ring reached the seafloor and then pulled to the surface at a rate of approximately
Table 2

Summary of horizontal de-correlation length scales $(m)$ for acoustical layers in Monterey Bay, CA.

\begin{tabular}{lll}
\hline Date & \# Profiles & De-correlation length scale $(\mathrm{m})$ \\
\hline 071506 & $6.43 \times 10^{4}$ & 0.03 \\
$071706 \mathrm{a}$ & $1.64 \times 10^{4}$ & 0.45 \\
$071706 \mathrm{~b}$ & $1.49 \times 10^{4}$ & 0.41 \\
071806 & $9.31 \times 10^{4}$ & 0.06 \\
071906 & $4.96 \times 10^{4}$ & 0.10 \\
072206 & $1.22 \times 10^{5}$ & 0.76 \\
072306 & $6.20 \times 10^{4}$ & 0.28 \\
$072406 \mathrm{a}$ & $3.10 \times 10^{4}$ & 0.09 \\
$072406 \mathrm{~b}$ & $3.10 \times 10^{4}$ & 0.08 \\
072606 & $2.68 \times 10^{4}$ & 0.13 \\
072506 & $2.18 \times 10^{4}$ & 1.05 \\
080406 & $9.09 \times 10^{4}$ & 2.67 \\
080606 & $2.61 \times 10^{5}$ & 1.25 \\
\hline
\end{tabular}

Dates data were collected are presented as month, day, year (mmddyy), with the number of vertical "profiles" used in each autocorrelation analysis. The shaded section represents the data collected at nighttime.

$1 \mathrm{~m} / \mathrm{s}$. Samples were preserved in $5 \%$ buffered formalin in seawater for later analysis. Net sampling focused directly on thin layers was not possible during this study, however, water column integrated zooplankton tows showed that zooplankton captured in the net were dominated by $\sim 1 \mathrm{~mm}$ copepods. Three copepod genera made up more than $90 \%$ of the zooplankton both numerically and by biomass (see detailed analysis in Benoit-Bird et al., this issue). The relatively limited diversity of body types and the lack of any extremely strong scatterers such as gastropods or those with air inclusions suggests that acoustic scattering can reasonably used as an estimate of relative abundance of relatively large and mobile zooplankton over depth.

\subsection{Data analysis}

\subsubsection{Definition of layers}

For the bio-optical data sets collected by AUVs, the treatment of the data to identify layers was as follows. As the vehicles were undulating in the water column, each parameter for the entire mission was first partitioned into separate casts. As shown in Fig. 2, for each upcast and downcast, a running $5 \mathrm{~m}$ vertical median was taken for each profile. The measurement with the greatest difference from the median for each parameter was identified as the peak value for each cast. The upper and lower edges of the layer were then determined by finding the points at which the measured values crossed the running median above and below the peak. The depth of the layer was defined as the point at which the layer reached a maximum value. The thickness of the layer was calculated as the range of values within half the peak intensity of the layer, sometimes called the full width at half maximum (FWHM). Features were defined as thin layers when their peaks exceeded 1.25 times the local background with a FWHM thickness less than $3 \mathrm{~m}$. The background was defined as the point under the peak which intersected a baseline drawn between the minimum observation in each individual profile above and below the defined layer. This criterion is somewhat different from the commonly cited definition of thin layers which uses a factor of 3 times higher than the global rather than local background values (Dekshenieks et al., 2001) but is robust when layers are found in a variable background, e.g., there are other patches in the plankton, a situation common in Monterey Bay.

For defining acoustic layers, a running, $5 \mathrm{~m}$ vertical median was taken for each echosounder ping. The points at which the layer crossed above the running median were used to define the upper and lower edges of the layer. The average value of these two 


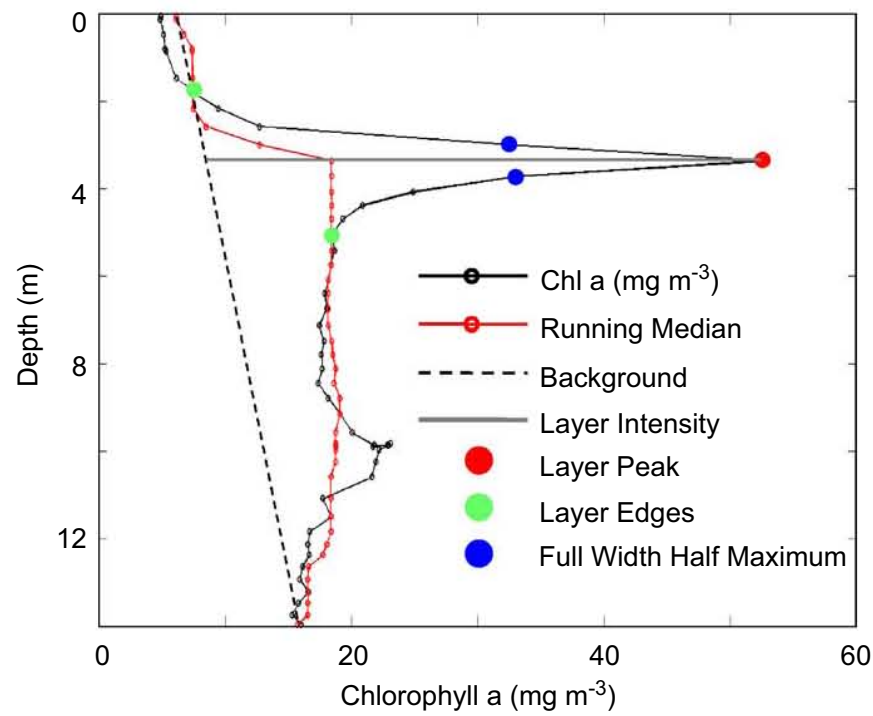

Fig. 2. An example depth profile of Chlorophyll a measured by a REMUS AUV during the LOCO experiment on July 14, 2006 (black line), which met the criteria of a thin layer. In order to define a thin layer, a series of steps were taken, the first being a running $5 \mathrm{~m}$ vertical median for each profile (red line). The measurement with the greatest difference from the median for each parameter was identified as the peak value for each cast (red circle). The upper and lower edges of the layer were then determined by finding the points at which the measured values crossed the running median above and below the peak (green circles). The thickness of the layer was calculated as the range of values within half the peak intensity of the layer, sometimes called the full width at half maximum (FWHM; blue circles). The local background was defined by the lowest values above and below the identified layer. Features were defined as thin layers when their peaks exceeded 1.25 times the local background (grey line), with a FWHM thickness (the distance between the blue circles) less than $3 \mathrm{~m}$. (For interpretation of the references to colour in this figure legend, the reader is referred to the web version of this article.)

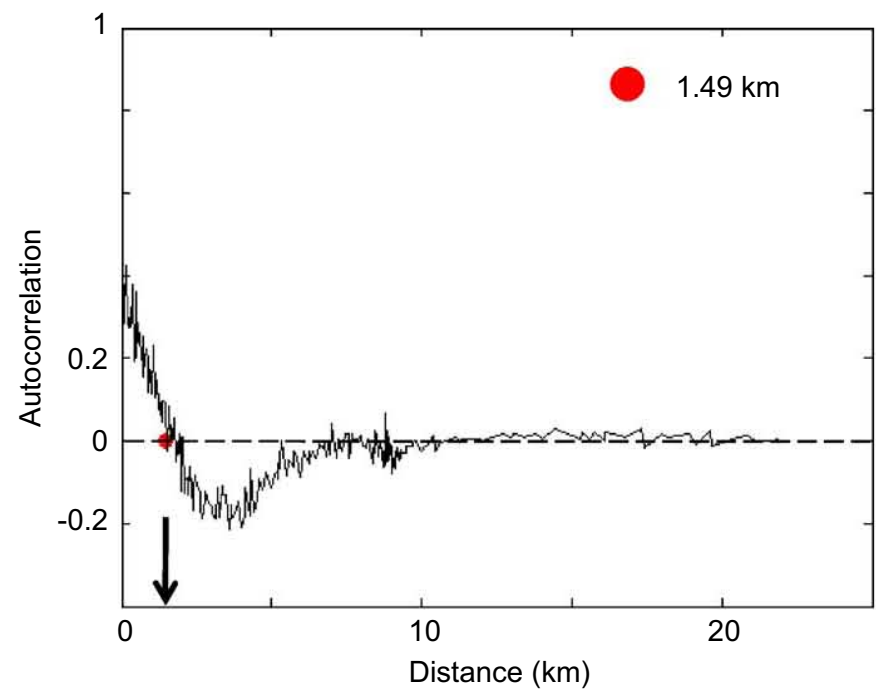

Fig. 3. Autocorrelation of the distance-sorted horizontal distribution of mean chlorophyll a within layers. This example is taken from October 16, 2008, illustrating the zero crossing point and identifying the decorrelation length scale of $1.49 \mathrm{~km}$

crossing points was used to define the local background value. The depth of the layer was defined as the point at which the layer reached a maximum value. The thickness of the layer was calculated as the range of values within half the peak intensity of the layer, or the FWHM. Features were defined as thin layers when their peaks exceeded 1.25 times the local background with a FWHM thickness less than $3 \mathrm{~m}$. The mean volume backscatter for each identified layer was calculated in the linear domain for each echo over the full depth range the feature exceeded the background values. This resulted in a minimum averaging of 30 values, necessary for valid assessment of volume scattering.

It should be noted that the sampling pattern for this study was weighted to cross shore rather than along shore (less so for the acoustic data than the optical measurements; Fig. 1), which could influence the magnitude of the horizontal decorrelation length scales.

\subsubsection{Decorrelation length scales}

To quantify the decorrelation length scales within each layer, the mean values for each bio-optical parameter and volume backscattering strength were used, which does not account for any vertical variability of the layers. If no layer was detected, the mean value of the water column profile (or acoustic ping) was used. This ensures maximum variance along a given transect, provides a conservative estimate of the decorrelation length scale, and for the acoustic data provides adequate averaging for the measurement of volume scattering. For the acoustic data, additional analyses were conducted on data, where a moving window average of 10 and 50 pings was applied to further increase the number of samples used to estimate volume scattering. For each mission (Tables 1 and 2), a 1-dimensional autocorrelation algorithm was applied by calculating the autocovariance function with mean value of each parameter subtracted. The function is then normalized by the maximum zero lag covariance, which results in an autocorrelation function with limits between 1 and -1 . The correlation function value of zero (the zero crossing point) represents the maximum lag (horizontal distance scale) beyond which points are no longer statistically dependent, and thus determines the decorrelation scale (Yu et al., 2002; Fig. 3). Computing an autocorrelation function for various lags determines the dominant spatial scales in layer variability within a selected range of lags, and is determined by the spatial sampling of the AUV and ship for a given mission. As indicated by Yu et al. (2002), when determining critical scales by a sequential sampling scheme with the AUV, there is a potential for error as a result of the Doppler-shift effect (Haury et al., 1983). In these studies however, currents were on the $0.25 \mathrm{~m} \mathrm{~s}^{-1}$ or less with a sampling speed of $2 \mathrm{~m} \mathrm{~s}^{-1}$, so this effect would be expected to be minimal.

Spatial aliasing can occur if the sampling resolution is lower than the decorrelation found (Yu et al., 2002). For each parameter, the horizontal distance between peaks of identified layers was measured to provide the horizontal resolution of the measurement. This is important as the undulations made by the AUV, together with the depth location of the layers, determines the distance. It was also important to undergo this process for each bio-optical parameter as the sampling frequencies were different. The peak of the histogram for all measurements of each parameter was then determined. For chlorophyll a the horizontal resolution was $\sim 50 \mathrm{~m}$, meaning there were 20 observations made for a decorrelation length scale of $1 \mathrm{~km}$, thus adequate to preclude spatial aliasing. The resolution for bioluminescence was also $50 \mathrm{~m}$ and optical backscatter was $90 \mathrm{~m}$. As the echosounder was vertically sampling, the horizontal resolution was the distance interval between pings (see above).

\section{Results and discussion}

\subsection{Horizontal distribution of layers}

Results from the combined bio-optical and acoustical data sets from the northeast section of Monterey Bay study area showed a high degree of layering with much of the layering occurring near 


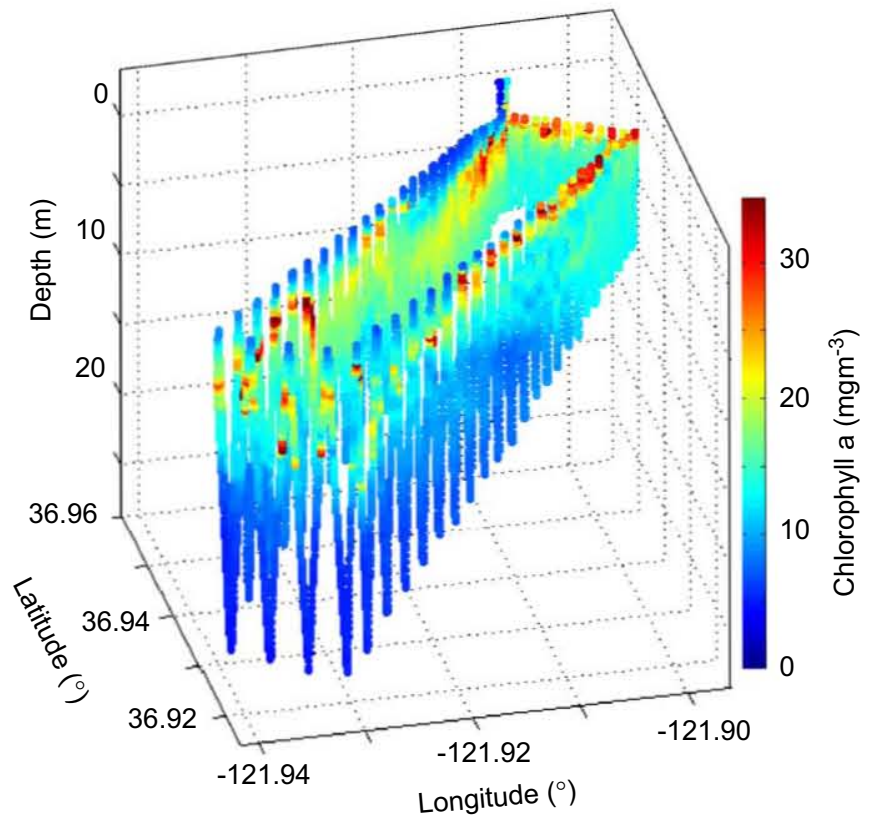

Fig. 4. Chlorophyll a as a function of geographic location and depth measured by a REMUS AUV during the LOCO experiment on July 14, 2006. Data trace illustrates the dimensionality of the layering and the intensity of the phytoplankton signal that occurred during this period. Two-dimensional slices of this data are shown in Fig. 4. For scale, the dimensions of the sampling rectangle were 5 by $1 \mathrm{~km}$.

the surface (Figs. 4 and 5). Despite strong physical gradients in this region, identified layers were often decoupled from isopycnal gradients (Fig. 5f). This has been shown in other chlorophyll fluorescence studies in this region with diatoms showing a strong coherence to the physical stratification, while dinoflagellates migrate vertically and are weakly correlated with stratification (Sullivan et al., this issue). Active swimming is an important mechanism controlling thin layers of both zooplankton (Gallager et al., 2004; McManus et al., 2005; Benoit-Bird et al., this issue) and motile phytoplankton (Klausmeier and Litchman, 2001) and one of the primary reasons for the decoupling between physical and biological layering. It is because these layers are often decoupled from the physical structure of the water column that an assessment of the variance within the layers is appropriate. Previous studies have assessed variance in the horizontal distribution of biological communities, but have done so by either a fixed-depth interval (Yu et al., 2002), or by isopycnal gradients (Denman and Powell, 1984; Mackas et al., 1985; Owen, 1989; Franks and Jaffe, 2001; Lennert-Cody and Franks, 1999). While certainly valid with non-motile phytoplankton communities in some conditions (i.e., internal waves; LennertCody and Franks, 2002), in areas where motile species are prevalent, such as Monterey Bay (Omori and Hamner, 1982; Cheriton et al., 2007; Ryan et al., 2008a), and in all cases for zooplankton, horizontal decorrelation length scales of plankton are better described by targeting the layers themselves (Figs. $5 \mathrm{~g}$ and 6).

\subsubsection{Bio-optical layers}

Bio-optical thin layers were common in all years measured in this study (Tables $1 \mathrm{a}$ and $1 \mathrm{~b}$ ). Analyses of variance (ANOVA) showed that the detection rate of chlorophyll a $(F=4.52, \mathrm{df}=3$, $35, p<0.01)$, bioluminescence $(F=3.65, \mathrm{df}=3,16, p<0.05)$ and optically scattering layers $(F=3.48, \mathrm{df}=3,35, p<0.05)$ varied as a function of year. Post-hoc tests with Bonferonni correction for multiple comparisons identified the source of these differences. Chlorophyll a thin layers were usually found in greater than $50 \%$ of the profiles, however there were significantly higher rates of layer detection in 2002 and 2003 compared to 2006 and 2008. Similarly, there were more bioluminescent layers found during the 2003 and 2003 field efforts (Table 1a). Layers of optical backscatter occurred in more than one third of profiles with a slight but significant decrease in occurrence during the LOCO experiment in 2006 ( $p<0.5$ for all comparisons). A multivariate ANOVA revealed that year also had an effect on the thickness, depth, and maximum intensity of layers $(F=388$, $\mathrm{df}=18.8$, $p<0.05$ ). Post-hoc analyses corrected using the Bonferonni method for multiple comparison showed that coincident with fewer chlorophyll a layers identified in 2002 and 2003, the layers during these years were also significantly deeper and more highly concentrated than those measured in 2006 and 2008. During the LOCO experiment in 2006, chlorophyll a layers were found to be shallower and also thicker than other years. These features were also seen in optical backscatter for the same time period $(p<0.05$ for all comparisons; Table 1b). Deeper and thinner layers were found in 2002, 2003, and 2008, which are consistent with near bottom nephloid layers (Moline et al., 2004). While sample sizes for bioluminescence layers were too small to allow a full interyear comparison of layer features, they were similar to other biooptical layers found in 2002 and 2003 in that they were relatively deep and comparatively thin. Bioluminescent layers were offset from the chlorophyll, suggesting that the largest signals were from zooplankton. Previous analysis of the measured bioluminescence signals from 2003 confirmed that the largest bioluminescent signals were from zooplankton located below the maximum chlorophyll layer (Moline et al., 2009).

\subsubsection{Acoustic backscatter layers}

As highlighted in Benoit-Bird et al. (this issue), acoustic scattering layers measured in 2006 were detected in approximately $40 \%$ of the profiles sampled. These layers occurred at both the surface and at depth and, when present, tended to be horizontally continuous (Fig. 6). Analyzing the physical lengths of the acoustic layers revealed a median length of $103 \mathrm{~m}$ for the entire data set. There was a difference in the lengths of these layer sheets between daytime and nighttime, with significantly longer lengths ( $\sim 20 \mathrm{~m}$ longer) found in the daytime sample collections ( $t$-stat $=-2.73, p=0.005, \mathrm{df}=30$; Fig. 7). Additionally layers were more abundant at night (Fig. 7), which is important for the interpretation of Benoit-Bird et al. (this issue), which only examined nighttime layers.

\subsection{Horizontal length scales of layers}

The decorrelation length scales from bio-optical measurements were significantly longer than those from acoustic measurements. As with the bio-optical layer statistics, the decorrelation length scale for chlorophyll was significantly longer in 2002/2003 than in 2006/2008 ( $t$-stat $=8.10, p<001, \mathrm{df}=15$ ), with mean horizontal distance scales of $6.76 \pm 2.40$ and $1.04 \pm 1.14 \mathrm{~km}$, respectively (Table 1 ). Looking at the locations and geographic extent of the AUV mission in Monterey Bay (Fig. 1), one may suspect that there was a potential bias of the nearshore missions during LOCO experiment (2006). However, there were no significant differences between the mean decorrelation scales between 2006 and 2008 despite very different coverage. Mean decorrelation scales for bioluminescence $(3.18 \mathrm{~km})$ were approximately half that of chlorophyll a for $2002 / 2003$ (see above). For other years, the scales were even smaller $(20-600 \mathrm{~m})$ and at the limit of the sampling resolution suggesting that finer horizontal sampling than possible with the current AUV configuration may sometimes be needed to examine 

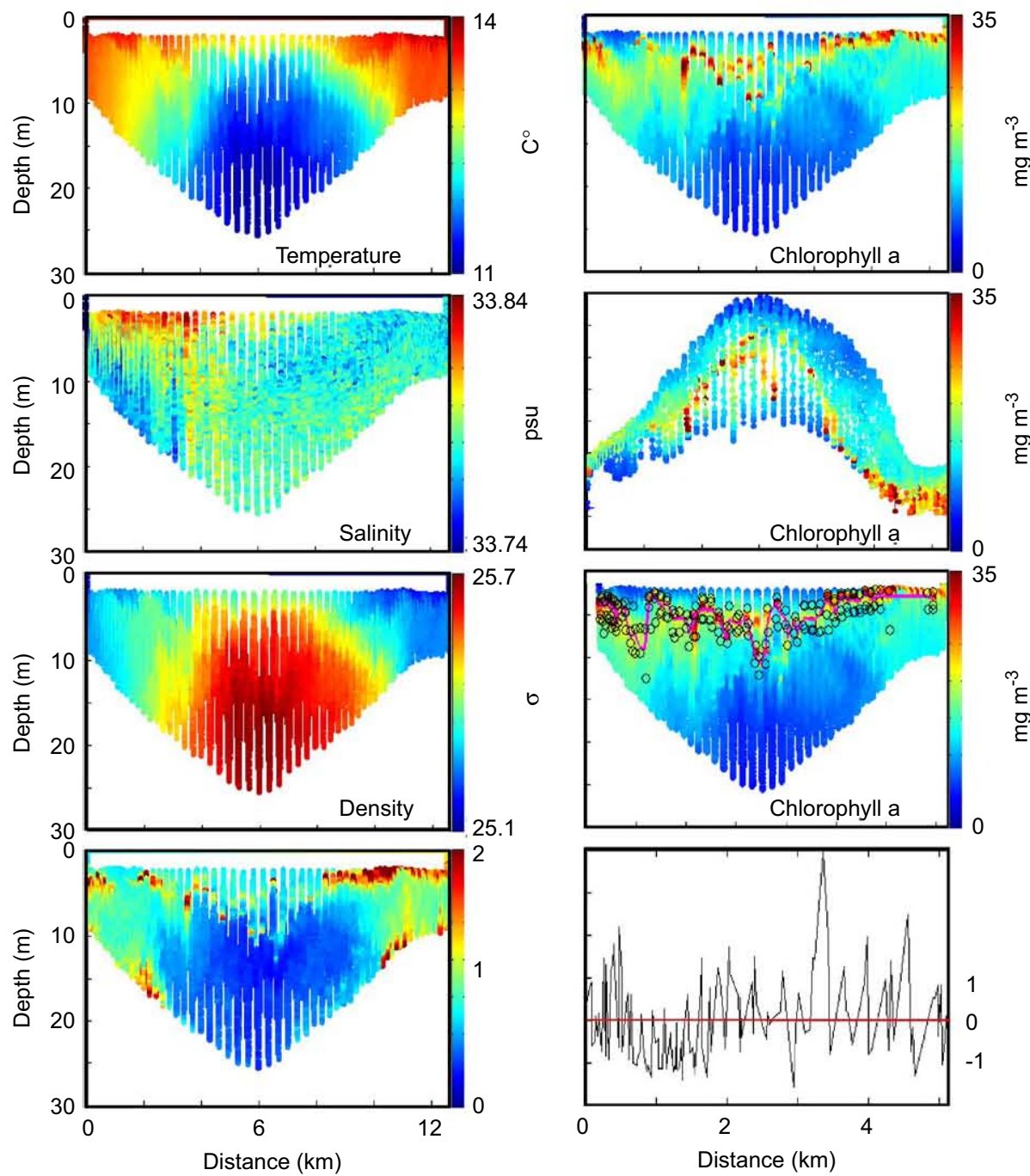

"E
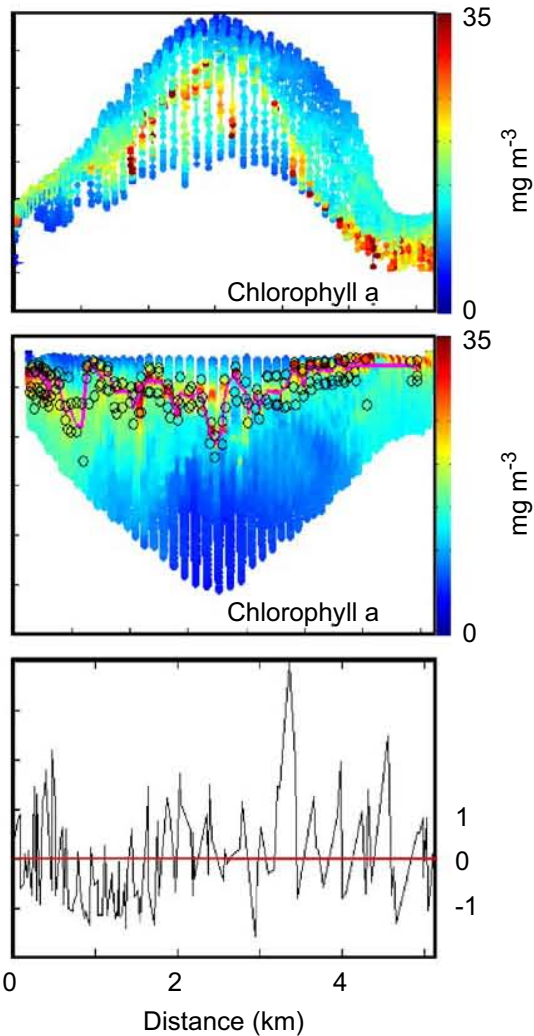

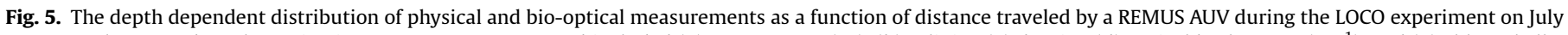

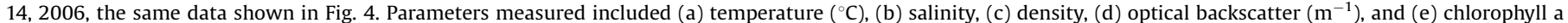

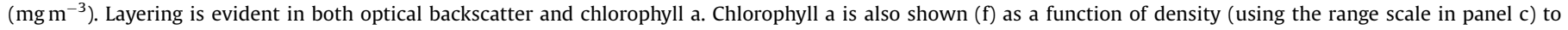

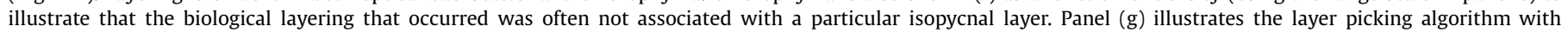

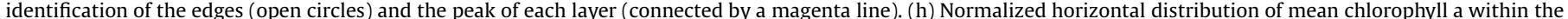

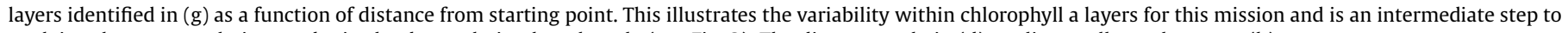
applying the autocorrelation to obtain the decorrelation length scale (see Fig. 2). The distance scale in (d) applies to all panels except (h).

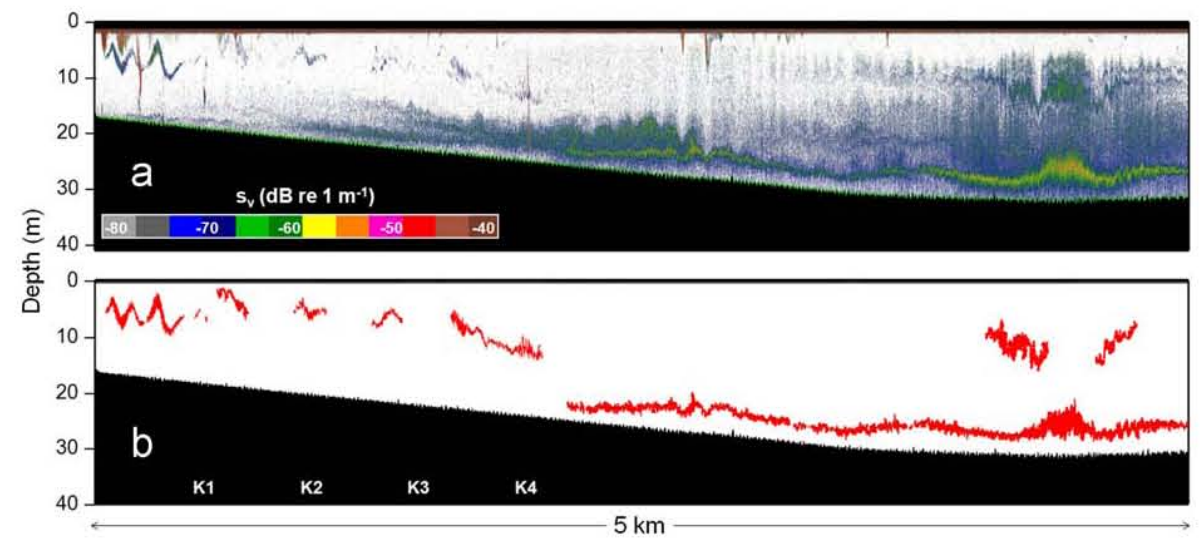

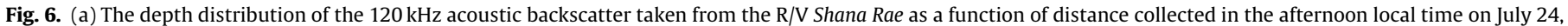

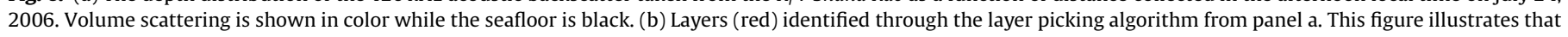

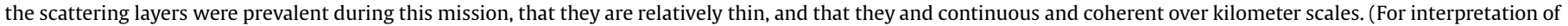
the references to colour in this figure legend, the reader is referred to the web version of this article.) 


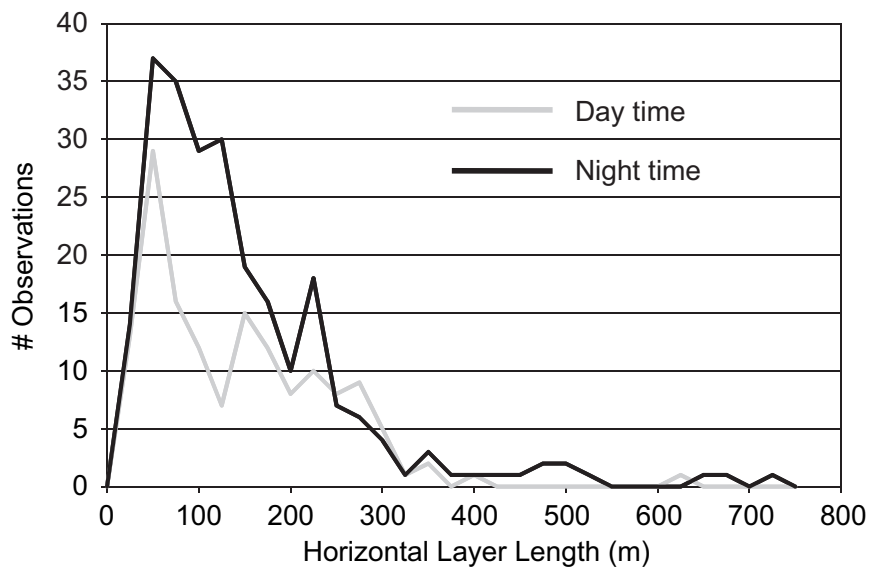

Fig. 7. Histogram of the physical length of coherent acoustic scattering layers collected during the daytime (grey) and nighttime (black) for all data collected (see Table 2). Layers were both significantly more abundant and spatially longer than during the day (see text). (For interpretation of the references to colour in this figure legend, the reader is referred to the web version of this article.)

the horizontal variance of bioluminescent thin layers. If it is accepted that the size of plankton patches and their variance generally scales inversely to the organisms size (Levin, 1992), with the largest patches represented by autotrophic phytoplankton, and less concentrated larger heterotrophic organisms in successively smaller patches (Hall and Raffaelli, 1993), then the decreasing decorrelation scales found for bioluminescence would suggest that these layers are composed of zooplankton, as opposed to phytoplankton. As shown in Benoit-Bird et al. (2009), bioluminescent layers were in fact correlated to acoustic scattering at frequencies relevant for zooplankton. Similar to chlorophyll a, optical backscatter showed longer decorrelation length scales associated with the early sampling years (Table $1 \mathrm{~b}$ ).

Decorrelation length scales of the horizontal variability in acoustic backscatter were extremely small with a mean scale of $0.50 \mathrm{~m}$ for the combined data set (Table 2). This mean length scale and the length scales measured during individual sampling sessions did not change when a sliding window average of either 10 pings or 50 pings was applied to the data, suggesting that inadequate averaging in volume scattering estimates and instrument noise are not responsible for the length scales measured. This length scale is on the order of the horizontal resolution of the sampling, which is reasonable given that the echosounder is imaging at near the scale of the relatively large and mobile individual zooplankton and ichthyoplankton that can be detected within the layers at $120 \mathrm{kHz}$. The short length scale we measured is consistent with field measurements of a number of species of zooplankton (e.g., Mackas and Boyd, 1979; Tsuda et al., 1993). The differences in length scales between phytoplankton and zooplankton observed here is also consistent with the modeling results of Abraham (1998) that show zooplankton density may be almost as variable at short scales as long ones as a result of turbulent stirring and interactions with phytoplankton while phytoplankton show substantially less fine scale structure. As with differences with the horizontal coherence of the layers between day and night, there was a significant difference in the mean decorrelation length scale of zooplankton layers between day $(0.24 \mathrm{~m})$ and night $(1.34 \mathrm{~m})$ sampling $(z=-1.47, p=0.05, n=10)$. So, despite the finding that the horizontal length of the layer was shorter during the night, there was less variability within them at night.

\subsection{Community structure and horizontal scales of layers}

In addition to defining the critical horizontal scales of biooptical and bio-acoustical variability within biological thin layers, significant differences in scales and layer characteristics were evident between years. While it is well known that the physical environment is a key forcing variable in the formation and structuring of thin layers (Franks, 1995; Osborn, 1998; Dekshenieks et al., 2001; McManus et al., 2003; Birch et al., 2008; Ryan et al., 2008b), it is clear that it cannot account for the formation of some layers, particularly those that are mediated by behavior (Donaghay et al., 1992; Rines et al., 2002; Menden-Deuer, 2008, Benoit-Bird et al., 2009). The community structure is therefore an important consideration. In the initial two years of bio-optical data presented here (2002/2003), layers were generally less variable, were found in more profiles, and were deeper. Examination of these data showed chlorophyll a layers were coupled to the physical gradients in the water column (Moline et al., 2009). Published data for these years also identify diatoms as the dominant autotroph in layers in Monterey Bay (Rines et al., 2002; McManus et al., 2008). In fact, Jester et al. (2009), using a 6year time series has documented a shift in Monterey Bay from diatom dominance to dominance by mixed dinoflagellates, including dinoflagellate species that were previously undocumented in the area (Curtiss et al., 2007). This transition was seen in 2004, between the years showing significant differences in critical horizontal length scales. Additional data available since 2004 is supportive of the conclusion of transition to a phytoplankton community dominated by dinoflagellates (Rines et al., 2006; Ryan et al., 2008a; Rines et al., this issue; Sullivan et al., 2009). Although diatoms can influence layer dynamics by change in buoyancy, dinoflagellates dominating this period of the study can modify layer continuity, thickness, and intensity by behavior, (Menden-Deuer, 2008), which would significantly influence the horizontal variability and decorrelation length scales of layers as documented here in bio-optical measurements (Table 1a,b). In addition, linking plankton patch dynamics solely to the physical environment (Franks 1995; Stacey et al., 2007; Mitchell et al., 2008; Ryan et al., 2008b), may be problematic in a region such as Monterey Bay where the plankton community structure dominates layering via behavior and vertical migration (Benoit-Bird et al., 2009). This transition has undoubtedly had an influence on the trophic food web, in particular the zooplankton community, and the nutrient dynamics of the system, however, this has not been examined. The occurrence of dinoflagellates has been documented to be increasing in coastal regions around the globe (Heisler et al., 2008), making the findings with regard to the spatial scales of layers applicable to other regions.

\subsection{Sampling and spatial scales of layers}

The previous section identified community structure as an important determinant in the modifying, here decreasing, the horizontal length scales of bio-optical layering. Results also show the decorrelation length scales of acoustic layers to be on the order of the distance between pings, especially during the daytime. As has been documented for the vertical structure of thin layers (see Cowles et al., 1998), sampling of these layers is a critical issue to evaluating properties, trophic impacts, and chemical modifications of layers. While the technology has greatly improved to sample vertical thin layers using autonomous profilers (Donaghay et al., 1992; Sullivan et al., this issue), sampling the horizontal dimension of thin layers near synoptically is still a challenge. As mentioned above, the simultaneous measurements targeting multiple trophic levels should also be a goal. Here and in Benoit-Bird et al. (this issue) a ship-mounted echosounder was used in combination with AUVs to evaluate the horizontal scales of thin layers and identify the range of scales that would need to be sampled to identify layer continuity and 
patch size. While this coordinated effort was able to capture the horizontal length scale variability of layers, there are improvements to the platform-sensor combination that may have the potential to improve resolution. Clearly the sampling frequency of the measurements, especially the bio-optical parameters, could be increased. A modified bioluminescence sensor described by Herren et al. (2005), for example, can now sample at $60 \mathrm{~Hz}$, which would improve the horizontal resolution by at least an order of magnitude. An ultra-high sampling frequency chlorophyll a fluorometer is also under development for the AUV (Bensky et al., 2008), which would have a significant effect on resolving the micro-scale. Although technically challenging, the installation of calibrated multi-frequency echosounders on AUVs, has the potential to improve the measurement of the horizontal extent of thin layers. AUV platforms would provide greater control of the vertical positioning of the echosounders relative to the layer targets, increasing the horizontal resolution by measuring layers in the narrowest parts of the sonar beams, and would provide data from collocated bio-optical sensors for concurrent measures of different trophic levels, chemistry and physics. Even though AUVs are now commonly used as scientific platforms (Dickey et al., 2008), the AUV platform itself could also be enhanced to identify layers and improve sampling by feature identification. This has been done with chemical plume tracking by an AUV (Farrell et al., 2005), and has recently been attempted using chlorophyll fluorescence to identify locations for water sampling by an AUV (Py et al., 2007). Swarming behavior in multiple AUV systems has also been demonstrated (Ögren et al., 2004), an approach that would greatly improve the near synoptic coverage of layers.

\section{Conclusions}

Results here and in Benoit-Bird et al. (this issue) highlight the advantages of combining sensors and platforms to examine layering of multiple trophic groups simultaneously. The horizontal decorrelation length scales of the bio-optical layers themselves were quantified in Monterey Bay, CA over a 6-year period while the acoustic scattering layers were only examined in 2006. While the length scales were unique to each measured parameter, there was a significant decrease in the decorrelation length scale over time, which coincides with a documented shift in the plankton community in Monterey Bay. A significant diel pattern was observed in the acoustic scattering layers with significantly longer decorrelation length scales at night when more layers were observed but when these layers were smaller in their horizontal extent. These shifts highlight the importance of considering plankton behavior and time of day with respect to scale, when studying layers. The changes in horizontal length scales also highlight the challenges of sampling these phenomena. New advances in sensors and autonomous underwater platforms hold great promise for better resolving the horizontal extent of optical and acoustical scattering layers in the coastal ocean.

\section{Acknowledgements}

We thank the many students that assisted in AUV operations in Monterey Bay, CA including J. Connolly, D. Elmore, J. Morgan, C. Boland, and Jenn Yost. We also thank S. Blackwell and the crew of the R/V Paragon for field support and data analysis for earlier AUV operations. James Christmann, the captain of the R/V Shana Rae is thanked for his field support in collection of acoustic data. Amanda Ashe, Percy Donaghay, D. Van Holliday, Margaret McManus, and Timothy Cowles facilitated the 2006 field work.
We also thank MBARI for their continued support of operations in Monterey Bay, CA.

Special thanks go to the special editor J. Sullivan and 2 anonymous reviewers for their excellent feedback to improve the manuscript. This work was funded by the Office of Naval Research through Young Investigator Program (N00014-05-1-0608 to K. Benoit-Bird, N00014-03-1-0341 to M. Moline) and by N00014-061-0739 to M. Moline. Field support was also provided by ONR DRI (LOCO, AOSN II) and MURI (ASAP, ESPreSSo) programs.

\section{References}

Abraham, E.R., 1998. The gernation of plankton patchiness by turbulent sturring Nature 391, 577-580.

Benoit-Bird, K.J., Moline, M.A., Waluk, C.M., Robbins, I.M., 2009. Integrated measurements of acoustical and optical thin layers I: Vertical scales of association. Continental Shelf Research, this issue, doi:10.1016/j.csr.2009.08.001.

Benoit-Bird, K.J., Cowles, T.J., Wingard, C.E., 2009. Edge gradients provide evidence of ecological interactions in planktonic thin layers. Limnology and Oceanography 54, 1382-1392.

Bensky, T., Clemo, L., Gilbert, C., Neff, B., Moline, M., Rohan, D., 2008. Observation of nanosecond laser induced fluorescence of in vitro seawater phytoplankton. Applied Optics 47, 3980-3986.

Birch, D.A., Young, W.R., Franks, P.J.S., 2008. Thin layers of plankton: formation by shear and death by diffusion. Deep-Sea Research I 55, 277-295.

Bissett, W., Arnone, R., Davis, C., Dickey, T., Dye, D., Kohler, D., Gould, R., 2004. From meters to kilometers: a look at ocean-color scales of variability, spatial coherence, and the need for fine-scale remote sensing in coastal ocean optics. Oceanography $17,32-43$.

Blackwell, S.M., Case, J.F., Glenn, S.M., Kohut, J., Moline, M.A., Purcell, M., Schofield, O., von Alt, C., 2002. A new AUV platform for studying near shore bioluminescence structure. In: Kricka, LJ. Stanley, P.E. (Eds.), Bioluminescence and Chemiluminescence Progress and Applications. World Scientific, pp. 197-200.

Blackwell, S., Moline, M., Schaffner, A., Garrison, T., Chang, G., 2008. Sub-kilometer length scales in coastal waters. Continental Shelf Research 28, 215-226.

Chang, G., Dickey, T., Schofield, O., Weidemann, A., Boss, E., Pegau, W., Moline, M. Glenn, S., 2002. Nearshore physical forcing of bio-optical properties in the New York Bight. Journal of Geophysical Research 107, 3133.

Cheriton, O.M., McManus, M.M., Holliday, D.V., Greenlaw, C.F., Donaghay, P.L., Cowles, T.J., 2007. Effects of mesoscale physical processes on thin zooplankton layers at four sites along the west coast of the US. Estuaries and Coasts 30 575-590.

Churnside, J., Sullivan, J., Donaghay, P., Rines, J., McFarland, M., Graff, J., Holliday, D. Greenlaw, C., Franks, P., Jaffe, J., 2006. $2000 \mathrm{~km}$ of thin layers. EOS Transactions, AGU 87, 36.

Cowles, T.J., Desiderio, R.A., Carr, M.-E., 1998. Small-scale planktonic structure: persistence and trophic consequences. Oceanography 11, 4-9.

Curtiss, C., Langlois, G., Busse, L., Mazzillo, F., Silver, M., 2007. The emergence of Cochlodinium along the California Coast (USA). Harmful Algae 7, 337-346.

Dale, A., Levine, M., Barth, J., Austin, J., 2006. A dye tracer reveals cross-shelf dispersion and interleaving on the Oregon shelf. Geophysical Research Letters 33, L03604.

Dekshenieks, M.M., Donaghay, P.L., Sullivan, J.M., Rines, J.E.B., Osborn, T.R., Twardowski, M.S., 2001. Temporal and spatial occurrence of phytoplankton thin layers in relation to physical processes. Marine Ecology Progress Series 223, 61-71.

Denman, K.L., Powell, T.M., 1984. Effects of physical processes on planktonic ecosystems in the coastal ocean. Oceanography and Marine Biology Annua Review 22, 125-168.

Deutschman, D., Bradshaw, G.A., Childress, W.M., Daly, K., Grunbaum, D., Pascual, M., Schumaker, N., Wu, J., 1993. Mechanisms of patch formation. In: Levin, S.A., Powell, T.M., Steele, J.H. (Eds.), Patch Dynamics. Springer Verlag, Berlin, pp. 184-209.

Dickey, T., Itsweire, E., Moline, M., Perry, M., 2008. Introduction to the limnology and oceanography special issue on autonomous and lagrangian platforms and sensors (ALPS). Limnology and Oceanography 53, 2057-2061.

Donaghay, P.L., Rines, H.M., Sieburth, J.M.N., 1992. Simultaneous sampling of fine scale biological, chemical, and physical structure in stratified waters. Archives of Hydrobiology 36, 97-108.

Farrell, J., Pang, S., Li, W., 2005. Chemical plume tracing via an autonomous underwater vehicle. IEEE Journal of Oceanic Engineering 30, 428-442.

Foote, K.G., Vestnes, G., Maclennan, D.N., Simmonds, E.J., 1987. Calibration of acoustic instruments for fish density estimation: A practical guide. International Council for the Exploration of the Sea Cooperative Research Report 144 Copenhagen, p. 57.

Franks, P.J.S., 1995. Thin layers of phytoplankton: a model of formation by nearinertial wave shear. Deep-Sea Research I 42, 75-91.

Franks, P.J.S., Jaffe, J.S., 2001. Microscale distributions of phytoplankton: initial results from a two-dimensional imaging fluorometer, OSST. Marine Ecology Progress Series 220, 59-72. 
Gallager, S.M., Yamazaki, H., Davis, C.S., 2004. Contribution of fine-scale vertical structure and swimming behavior to formation of plankton layers on Georges Bank. Marine Ecology Progress Series 276, 27-43.

Hall, S., Raffaelli, D., 1993. Food webs: theory and reality. Advances in Ecological Research 24, 187-239.

Haury, L., Wiebe, P., Orr, M., Briscoe, M., 1983. Tidally generated high-frequency internal wave packets and their effects on plankton in Massachusetts Bay. Journal of Marine Research 41, 65-112.

Heisler, J., Glibert, P., Burkholder, J., Anderson, D., Cochlan, W., Dennison, W. Dortch, Q., Gobler, C., Heil, C., Humphries, E., 2008. Eutrophication and harmful algal blooms: a scientific consensus. Harmful Algae 8, 3-13.

Herren, C.M., Haddock, S.H.D., Johnson, C.S., Orrico, C.M., Moline, M.A., Case, J.F., 2005. A multi-platform bathyphotometer for fine-scale, coastal bioluminescence research. Limnology and Oceanography: Methods 3, 247-262.

Hibler, L.F., Maxwell, A.R., Miller, L.M., Kohn, N.P., Woodruff, D.L., Montes, M.J., Bowles, J.H., Moline, M.A., 2008. Improved fine scale transport model performance using AUV and HSI feedback in a tidally dominated system. Journal of Geophysical Research 113, C08036 doi: 08010.01029/02008JC004739.

Hodges, B., Rudnick, D., 2006. Horizontal variability in chlorophyll fluorescence and potential temperature. Deep-Sea Research 53, 1460-1482.

Holliday, D.V., Donaghay, P.L., Greenlaw, C.F., McGehee, D.E., McManus, M.M., Sullivan, J.M., Miksis, J.L., 2003. Advances in defining fine- and micro-scale pattern in marine plankton. Aquatic Living Resources 16, 131-136.

Holliday, D.V., Pieper, R.E., Greenlaw, C.F., Dawson, J.K., 1998. Acoustical sensing of small scale vertical structures in zooplankton assemblages. Oceanography 11.

Jester, R., Lefebvre, K., Langlois, G., Vigilant, V., Baugh, K., Silver, M., 2009. A shift in the dominant toxin-producing algal species in central California alters phycotoxins in food webs. Harmful Algae 8, 291-298.

Klausmeier, C.A., Litchman, E., 2001. Algal games: the vertical distribution of phytoplankton in poorly mixed water columns. Limnology and Oceanography 46, 1998-2007.

Lee, C., Jones, B., Brink, K., Fischer, A., 2000. The upper-ocean response to monsoonal forcing in the Arabian Sea: seasonal and spatial variability. DeepSea Research Part II 47, 1177-1226.

Lennert-Cody, C., Franks, P., 2002. Fluorescence patches in high-frequency internal waves. Marine Ecology Progress Series 235, 29-42.

Lennert-Cody, C.E., Franks, P.J.S., 1999. Plankton patchiness in high-frequency internal waves. Marine Ecology Progress Series 186, 59-66.

Levin, S.A., 1992. The problem of pattern and scale in ecology. Ecology 73 , 1943-1967.

Lovejoy, S., Currie, W., Tessier, Y., Claereboudt, M., Bourget, E., Roff, J., Schertzer, D., 2001. Universal Multifractals and Ocean Patchiness: Phytoplankton, Physical Fields and Coastal Heterogeneity. Oxford University Press, Oxford, pp. 117-141.

Mackas, D., Boyd, C., 1979. Spectral analysis of zooplankton spatial heterogeneity. Science 204, 62-64

Mackas, D.L., Denman, K.L., Abbott, M.R., 1985. Plankton patchiness: biology in the physical vernacular. Bulletin of Marine Science 37, 652-674.

McManus, M.M., Alldredge, A.L., Barnard, A.H., Boss, E., Case, J.F., Cowles, T.J., Donaghay, P.L., Eisner, L.B., Gifford, D.J., Greenlaw, C.F., Herren, C.M., Holliday, D.V., Johnson, D., MacIntyre, S., McGehee, D.E., Osborn, T.R., Perry, M.J., Pieper, R.E., Rines, J.E.B., Smith, C.D., Sullivan, J.M., Talbot, M.K., Twardowski, M.S., Weidemann, A., Zaneveld, J.R., 2003. Characteristics, distribution, and persistence of thin layers over a $48 \mathrm{~h}$ period. Marine Ecology Progress Series 261, 1-19.

McManus, M.M., Cheriton, O.M., Drake, P.J., Holliday, D.V., Storlazzi, C.D., Donaghay, P.L., Greenlaw, C.F., 2005. Effects of physical processes on structure and transport of thin zooplankton layers in the coastal ocean. Marine Ecology Progress Series 301, 199-215.

McManus, M.M., Kudela, R.M., Silver, M.W., Steward, G.F., Donaghay, P.L., Sullivan, D.E., 2008. Cryptic blooms: are thin layers the missing connection?. Estuaries and Coasts 31, 396-401.

Menden-Deuer, S., 2008. Spatial and temporal characteristics of plankton-rich layers in a shallow, temperate fjord. Marine Ecology Progress Series 355, 2130 .

Mitchell, J., Yamazaki, H., Seuront, L., Wolk, F., Li, H., 2008. Phytoplankton patch patterns: seascape anatomy in a turbulent ocean. Journal of Marine Systems 69, 247-253.

Moline, M.A., Blackwell, S.B., Case, J.F., Haddock, S.H.D., Herren, C.M., Orrico, C.M. Terrill, E., 2009. Bioluminescence to reveal structure and interaction of coastal planktonic communities. Deep-Sea Research II 56, 232-245.
Moline, M.A., Blackwell, S.M., Von Alt, C., Allen, B., Austin, T., Case, J.F., Forrester, N., Goldsborough, R., Purcell, M., Stokey, R., 2005. Remote environmental monitoring units: an autonomous vehicle for characterizing coastal environments. Journal of Atmospheric and Oceanic Technology 22, 1797-1808.

Moline, M.A., Blackwell, S.M., Chant, R., Oliver, M.J., Bergmann, T., Glenn, S., Schofield, O.M.E., 2004. Episodic physical forcing and the structure of phytoplankton communities in the coastal waters of New Jersey. Journal of Geophysical Research 109, C12S05, doi:10.1029/2003JC001985.

Moline, M.A., Heine, E., Case, J.F., Herren, C.M., Schofield, O., 2001. Spatial and temporal variability of bioluminescence potential in coastal regions. In: Case, J.F., Herring, P.J., Haddock, S.H.D., Kricka, L.J., Stanley, P.E. (Eds.), Bioluminescence and Chemiluminescence 2000. World Scientific Publishing Company, Singapore, pp. 123-126.

Ögren, P., Fiorelli, E., Leonard, N., 2004. Cooperative control of mobile sensor networks: adaptive gradient climbing in a distributed environment. IEEE Transactions on Automatic Control 49, 1292-1302.

Omori, M., Hamner, W., 1982. Patchy distribution of zooplankton: behavior, population assessment and sampling problems. Marine Biology 72, 193-200.

Osborn, T.R., 1998. Fine structure, microstructure, and thin layers. Oceanography $11,36-38$.

Owen, R., 1989. Microscale and finescale variations of small plankton in coastal and pelagic environments. Journal of Marine Research 47, 197-240.

Py, F., Ryan, J., Rajan, K., Sherman, A., Bird, L., Fox, M., Long, D., 2007. Adaptive water sampling based on unsupervised clustering. EOS Transactions, AGU 88, 52

Rines, J., McFarland, M., Donaghay, P., Sullivan, J., Graff, J., 2006. Characterization of the Monterey Bay phytoplankton community during the 2005 LOCO (Layered Organization in the Coastal Ocean) experiment, and the importance of speciesspecific characteristics of the flora to the dynamics and properties of thin layers. EOS Transactions, AGU 87, 36.

Rines, J.E.B., Donaghay, P.L., Dekshenieks, M.M., Sullivan, J.M., Twardowski, M.S., 2002. Thin layers and camouflage: hidden Pseudo-nitzschia populations in a fjord in the San Juan Islands, Washington, USA. Marine Ecology Progress Series $225,123-137$.

Rines, J.E.B., McFarland, M., Donaghay, P.L., Sullivan, J.M., 2010. Thin layers and species-specific characterization of the phytoplankton community in Monterey Bay, California USA. Continental Shelf Research, this issue.

Rudnick, D., Davis, R., Eriksen, C., Fratantoni, D., Perry, M., 2004. Underwater gliders for ocean research. Marine Technology Society Journal 38, 73-84.

Ryan, J., Gower, J., King, S., Bissett, W., Fischer, A., Kudela, R., Kolber, Z., Mazzillo, F., Rienecker, E., Chavez, F., 2008a. A coastal ocean extreme bloom incubator. Geophysical Research Letters 35, L12602 doi: 12610.11029/12008GL034081.

Ryan, J.P., McManus, M.M., Paduan, J.D., Chavez, F., 2008b. Phytoplankton thin layers caused by shear in frontal zones of a coastal upwelling system. Marine Ecology Progress Series 354, 21-34.

Ryan, J.P., McManus, M.A., Sullivan, J.M. Physical, chemical and biological forcing of phytoplankton thin-layer variability in Monterey Bay, California. Continental Shelf Research, this issue.

Stacey, M.S., McManus, M.M., Steinbuck, J., 2007. Convergences and divergences and thin layer formation and maintenance. Limnology and Oceanography 52. 1523-1532.

Sullivan, J.M., Twardowski, M.S., Donaghay, P.L., Freeman, S.A., 2005. Use of optical scattering to discriminate particle types in coastal waters. Applied Optics 44, $1667-1680$.

Sullivan, J.M., Donaghay, P.L., Rines, J.E.B., 2009. Coastal thin layer dynamics: consequences to biology and optics. Continental Shelf Research, this issue, doi:10.1016/j.csr.2009.07.009.

Tsuda, A., Sugisaki, H., Ishimaru, T., Saino, T., Sato, T., 1993. White-noise-like distribution of the oceanic copepod Neocalanus cristatus in the subarctic North Pacific. Marine Ecology Progress Series 97, 39-46.

Wang, Z., Goodman, L. The evolution of a thin phytoplankton layer in strong turbulence. Continental Shelf Research, this issue, doi:10.1016/j.csr.2009.08.006.

Widder, E.A., Johnsen, S., Bernstein, S.A., Case, J.F., Neilson, D.J., 1999. Thin layers of bioluminescent copepods found at density discontinuities in the water column. Marine Biology 134, 429-437.

Yoder, J., McClain, C., 1987. Spatial scales in CZCS-chlorophyll imagery of the southeastern US continental shelf. Limnology and Oceanography 32, 929-941.

Yu, X., Dickey, T., Bellingham, J., Manov, D., Streitlien, K., 2002. The application of autonomous underwater vehicles for interdisciplinary measurements in Massachusetts and Cape Cod Bays. Continental Shelf Research 22, 2225-2245. 